\title{
Population Ageing Negatively Affects Productivity
}

\section{Vegard Skirbekk*}

Population ageing is likely to lead to lower productivity than what the situation would be if the population did not age. This is both because the workforce grows older and because a lower proportion of the population are working. Shorter working lives coupled with increased overall life expectancy, low fertility and ageing of the baby boomers both ages and shrinks the economically active share of the population. This is likely to have massive implications for work productivity and overall economic growth.

Over the last decades, despite longer life spans, working lives have become several years shorter than what was previously the norm. In many ageing economies, an average worker spends more years out of the workforce than in it even today. As life expectancy has continued to increase by more than a year every decade, it becomes increasingly difficult to keep the length of retirement fixed or just stabilise the proportion of people's lives that they spend in retirement.

Changing retirement incentives, such as gradually introducing actuarially neutral pension systems where pensions increase for every year spent in the workforce have been shown to moderately increase the age at retirement. However, unions are often opposed to increasing the retirement age and employers are often reluctant to hire older individuals. Furthermore, the type of jobs and the conditions employers could offer may lead many older individuals to opt for leisure rather than work. Moreover, introducing incentives to delay the exit from the labour market to later ages is a difficult and very time-consuming process. It can take decades to make the necessary changes to pension systems that would make it really in the individual's interest to retire at later ages.

An additional factor that could lead to declining productivity is that older employees on average exhibit a lower productive level than workers in the middle of their careers. This finding has been confirmed by a range of analyses of workers of different age groups. Several physical and mental abilities tend to decline as one grows older. Muscle mass, stamina, sensory abilities, health, learning ability and speed - all of these decrease with age. Hormone cures, mental training programmes and anti-ageing treatments are likely to remain only moderately effective, expensive and only used by a minority of the elderly population. Increasing education levels can counter the negative effects of population ageing but only to a certain extent, as the biological process, i.e., the

\footnotetext{
* Vegard Skirbekk, International Institute for Applied Systems Analysis, Schlossplatz 1, 2361 Laxenburg, Austria. Email: skirbekk@iiasa.ac.at
} 
cognitive and physical decline, is only marginally, if at all, affected by schooling. Therefore, even in the hypothetical case where the retirement age would increase sufficiently to keep the active-inactive ratio in the population constant, withinworkforce ageing would adversely affect productivity.

Empirical studies based on supervisors' ratings, quantity-quality measures or employer-employee matched datasets, suggest that on average, and particularly in jobs where the rate of technological change and learning requirements are high, age is negatively correlated with job performance. In occupations where experience and communication skills matter more, and technological change is moderate, older workers can perform about as well as they would in the middle of their careers. Hence, unless older workers completely specialise in professions where age does not decrease work capacity, their average productivity decreases with age.

Some positive implications of population ageing are likely to soften the decrease in aggregate productivity. For example increased international capital transfers may offset some of the detrimental effects of population ageing on economic growth, as investments may increasingly be placed in countries with younger population structures (and lower capital-worker ratios) and the returns paid back to ageing economies will be higher. Future health improvements and technological advances can lead to an increase in workforce productivity. But it is unlikely that these factors will be strong enough to more than partially offset the negative effects of a shrinking, ageing workforce. 